\title{
Synthesis, structure and metal ion binding of di-(1,8-naphtho)-16-crown-4 compounds
}

\author{
Lokman Torun, ${ }^{\text {a,b, }}$ " Peter Mueller, ${ }^{\mathrm{c}}$ Xiaodan Cao, ${ }^{\mathrm{b}}$ and Richard A. Bartsch \\ ${ }^{a}$ TUBITAK MAM, Chemistry Institute, Gebze, Kocaeli 41470, Turkey \\ ${ }^{b}$ Department of Chemistry and Biochemistry, Texas Tech University, Lubbock, Texas \\ 79409-1061, USA \\ ${ }^{c} X$-Ray Diffraction Facility, Department of Chemistry, Massachusetts Institute of Technology, \\ Cambridge, Massachuestts 02139-4307, USA \\ E-mail:Lokman.Torun@mam.gov.tr
}

\begin{abstract}
The syntheses of two di(1,8-naphtho)-16-crown-4 compounds are described. In the X-ray structure of di(1,8-naphtho)-16-crown-4, the compound crystallizes in the orthorhombic space group Pna2 ${ }_{1}$ with four molecules per asymmetric unit. Alkali metal cation selectivities of the ionophores are assessed in solvent polymeric membrane electrodes.
\end{abstract}

Keywords: Small-ring crown ether, solid-state structure, alkali metal cation complexation

\section{Introduction}

Macrocyclic polyethers (crown ethers) are well known for their strong interactions with alkali metal and alkaline earth metal cations. ${ }^{1-4}$ Small-ring crown ethers with four oxygens (i.e., crown4 compounds) often exhibit selective complexation of $\mathrm{Li}^{+}$. In the past, we have reported studies of dibenzo-14-crown-4 1 (Figure 1) and its derivatives with one or two substituents attached to the central carbon atoms of three-carbon bridges. ${ }^{5-7}$ Due to rigidity in this ligand system, solidstate structures of its complexes provide insight into interactions of $\mathrm{Li}^{+}$with oxygen donor atoms. To probe the effect of expanding the crown ether ring from one with two 2-carbon and two 3-carbon bridges in dibenzo-14-crown-4 to four 3-carbon bridges, the synthesis of di-(1,8naphtho)-16-crown-4 2 was undertaken. We now describe the results of the synthetic endeavors, as well as the solid-state structure of $\mathbf{2}$ and its alkali metal cation selectivity in synthetic polymeric membrane electrodes. 


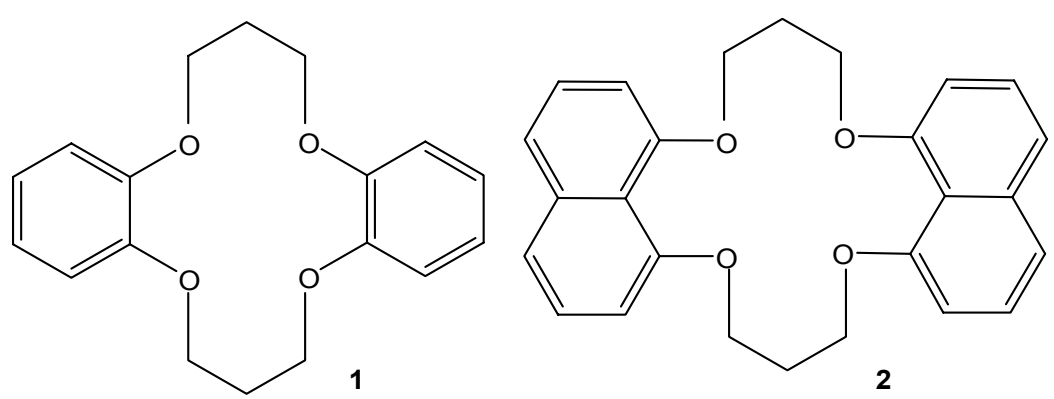

Figure 1. Structures of dibenzo-14-crown-4 1 and di-(1,8-dinaphtho)-16-crown-4 2.

\section{Results and Discussion}

\section{Synthesis}

The preparative route to 2 is presented in Scheme 1 .<smiles>O=S1(=O)Oc2cccc3cccc(c23)S1(=O)=O</smiles>

3

4
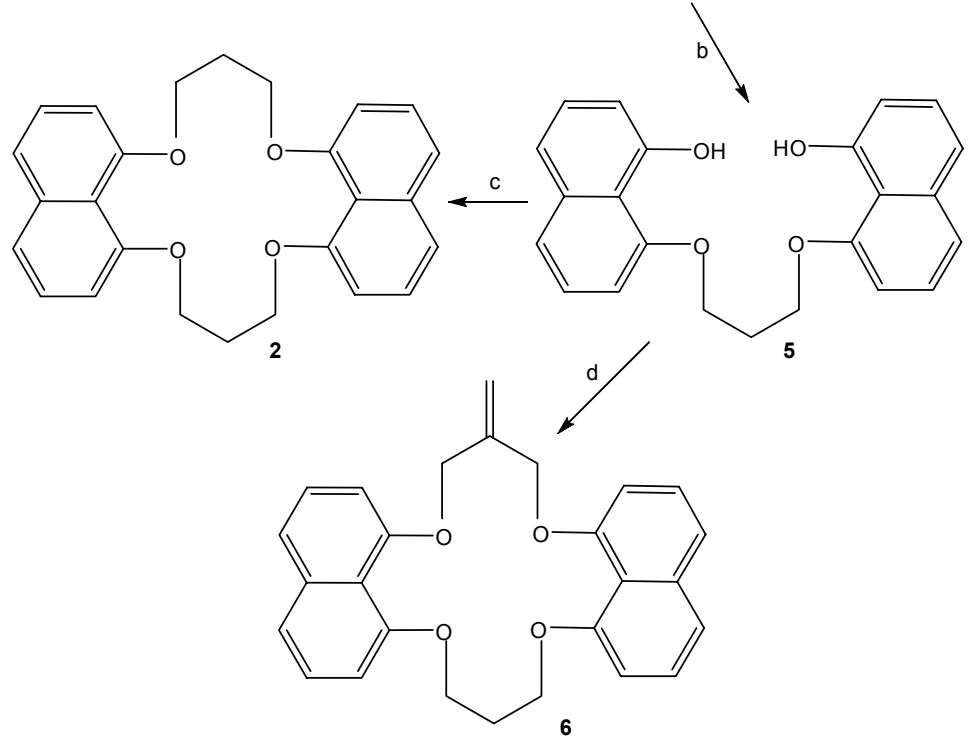

Scheme 1. Synthesis of di-(1,8-naphtho)-16-crown-4 2 and sym-(methylene)-di-(1,8-naphtho)16-crown-4 6: (a) i) $\mathrm{KOH}, 250{ }^{\circ} \mathrm{C}, 2 \mathrm{~h}$; ii) $6 \mathrm{~N} \mathrm{HCl}$; (b) 1,3-dibromopropane (0.5 equiv), $\mathrm{K}_{2} \mathrm{CO}_{3}$, $\mathrm{MeCN}$, reflux, $8 \mathrm{~h}$; (c) $\mathrm{MsO}\left(\mathrm{CH}_{2}\right)_{3} \mathrm{OMs}$ (1 equiv), $\mathrm{Cs}_{2} \mathrm{CO}_{3}, \mathrm{MeCN}, 80{ }^{\circ} \mathrm{C}$, overnight; (d) $\left(\mathrm{ClCH}_{2}\right)_{2} \mathrm{C}=\mathrm{CH}_{2}, \mathrm{Cs}_{2} \mathrm{CO}_{3}, \mathrm{MeCN}, 80^{\circ} \mathrm{C}$, overnight. 
Reaction of commercially available 1,8-naphthosultone 3 with $\mathrm{KOH}$ at $250{ }^{\circ} \mathrm{C}$ for 2 hours followed by treatment of the resultant mixture with $6 \mathrm{~N} \mathrm{HCl}$ gave a $54 \%$ yield of 1,8 dihydroxynaphthalene 4. Dropwise addition of a solution of 4 and 0.5 equivalent of 1,3dibromopropane in $\mathrm{MeCN}$ to a mixture of $\mathrm{K}_{2} \mathrm{CO}_{3}$ in $\mathrm{MeCN}$ at reflux followed by refluxing for 8 hours produced a $71 \%$ yield of the dinaphthol ether 5. Slow addition by syringe pump of a solution of equivalent amounts of 5 and the dimesylate of 1,3-propanediol in MeCN to a mixture of $\mathrm{Cs}_{2} \mathrm{CO}_{3}$ in $\mathrm{MeCN}$ at reflux followed by overnight reflux gave a $71 \%$ yield of di-(1,8-naphtho)16-crown-4 2.

Similar simultaneous addition of equivalent amounts of 5 and 3-chloro-2-chloromethyl-1propene in $\mathrm{MeCN}$ to a mixture of $\mathrm{Cs}_{2} \mathrm{CO}_{3}$ in $\mathrm{MeCN}$ at reflux then refluxing overnight provided a $71 \%$ yield of sym-(methylene)-di-(1,8-naphtho)-16-crown-4 6.

Other attempted cyclizations to form di-(1,8-naphtho)-16-crown-4 compounds were unsuccessful, including: i) reaction of 5, 3-chloro-2-chloromethyl-1-propene and $\mathrm{LiH}$ in $\mathrm{THF}$; ii) reaction of 5, 1,3-dichloroacetone and $\mathrm{LiH}$ in THF; and iii) reactions of $\mathbf{5}$ and epichlorohydrin with $\mathrm{LiOH}$ in $\mathrm{H}_{2} \mathrm{O}$ or aqueous THF, with $\mathrm{NaH}$ in DMF or with $\mathrm{Cs}_{2} \mathrm{CO}_{3}$ in $\mathrm{MeCN}$. Recovery of starting material $\mathbf{5}$ or evidence of decomposition products was observed in these cases.

\section{Solid-state structure of 2}

Compound 2 crystallized in the orthorhombic space group Pna2 $2_{1}$ with four molecules per asymmetric unit (Figure 2). While the 1,8-naphthalenedioxy moieties are well-behaved in all four independent molecules, the aliphatic 3-carbon bridges show signs of disorder (elongated thermal ellipsoids and relatively high residual electron density maxima in the vicinity). For the three of those disorders that could be resolved, the occupancy ratios of the two respective components were refined freely, while constraining the sum of the occupancies to unity. To counteract correlation effects arising from the disorders, similarity restraints on 1-2 and 1-3 distances and displacement parameters, as well as rigid bond restraints for anisotropic displacement parameters, were applied to all atoms. The disordered structure of one of the independent molecules is presented in Figure 3.

Altogether the structure of compound $\mathbf{2}$ is not well behaved. The diffraction pattern shows signs of non-merohedral twinning and the metric symmetry of the unit cell suggests the possibility of cell-doubling in the $b$-direction, especially when taking into account that the asymmetric unit contains four molecules. Neither suspicion could be corroborated, however. Extensive searches for alternative unit-cells and cell settings, as well as multiple orientations of the same unit-cell all performed with the program cell_now ${ }^{8}$ did not yield any usable results. Nevertheless, the refinement is reasonably stable and we are confident that the molecular model determined by means of this diffraction experiment reflects the chemistry of the compound accurately. 


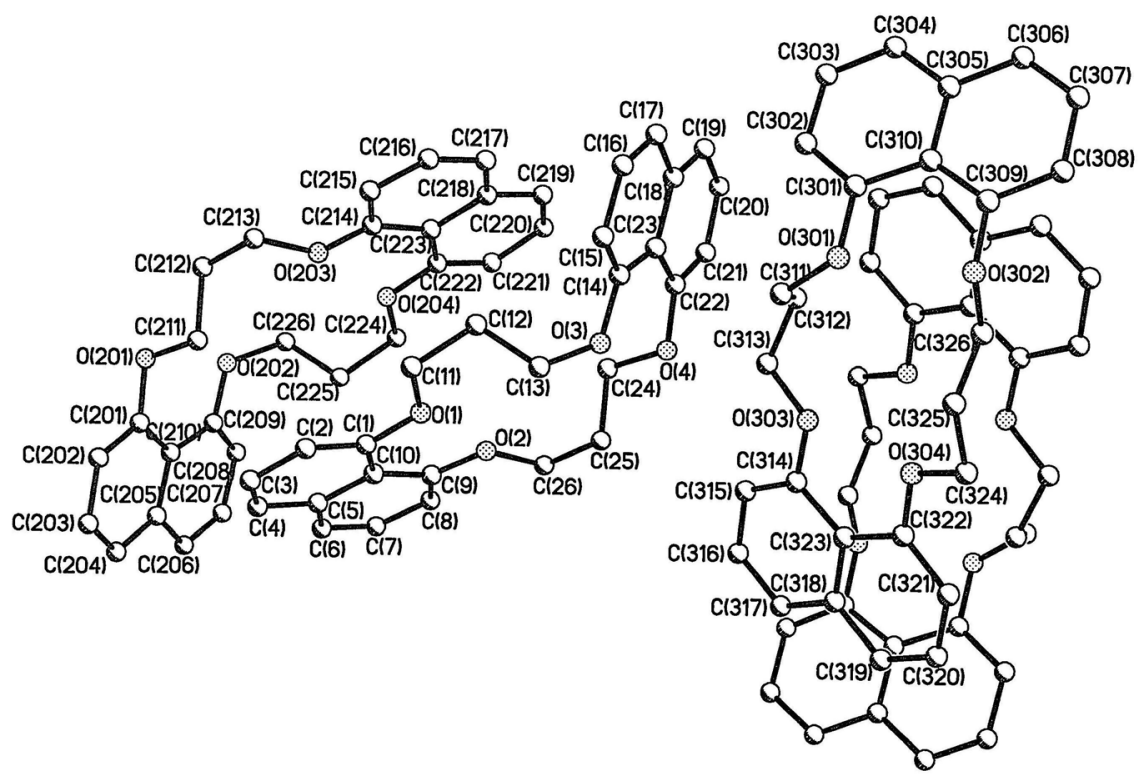

Figure 2. Ball-and-stick representation of the four crytallographically independent molecules with atomic labeling schemes for three of them. In the interest of clarity, the labels for the fourth molecule were omitted, but the labeling scheme follows the same principle as those of the other three molecules. Hydrogen atoms and atoms of the minor components of the disorders were omitted, as well.

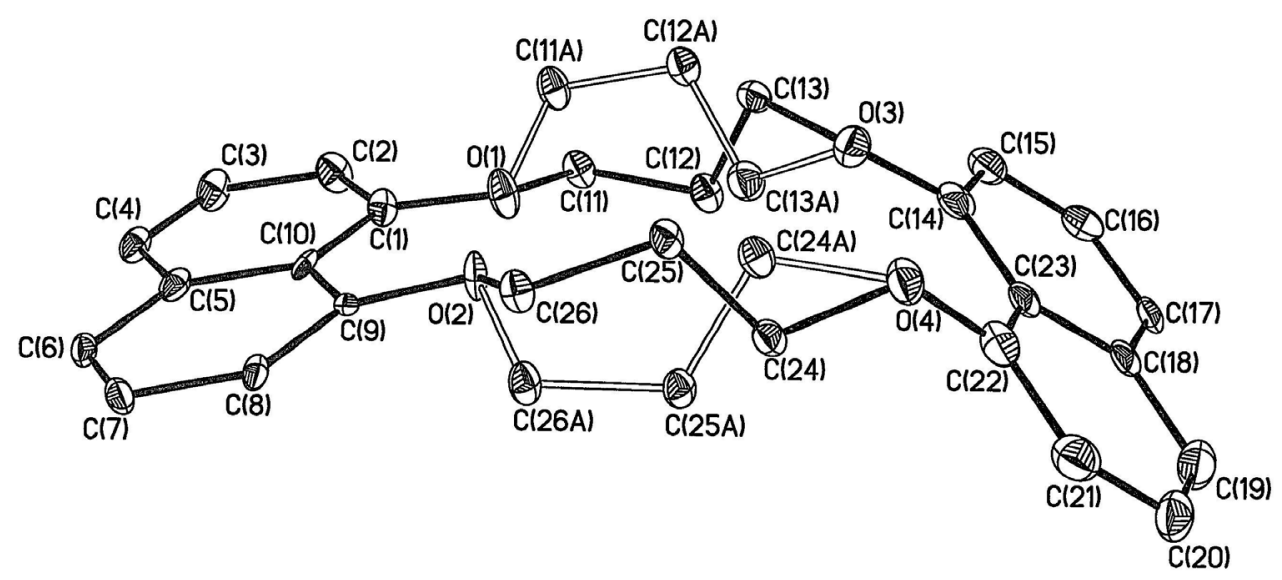

Figure 3. 50\% probability representation of one of the four independent molecules, showing the disorder of the aliphatic linkers (open lines for bonds between atoms in the minor component of the disorders). Hydrogen atoms were omitted for clarity

\section{Ionophoric response}

Using a previously described procedure, ${ }^{9}$ new crown-4 compounds $\mathbf{2}$ and $\mathbf{6}$ were incorporated into solvent polymeric membranes in which PVC was the polymer and $o$-nitrophenyl octyl ether (NPOE) was the membrane solvent. For ion-selective electrodes (ISEs) prepared from the 
membranes, potentiometric selectivities for one of the alkali metal cation relative to another were determined by the fixed interference method. ${ }^{10}$

Although it had been anticipated that the small cavity sizes of di-(1,8-naphtho)-16-crown-4 2 and sym-(methylene)-di-(1,8-naphtho)-16-crown-4 $\mathbf{6}$ would favor complexation of small alkali metal cations, preliminary experiments determined the greatest potentiometric response to $\mathrm{Cs}^{+}$ among the five alkali metal cations. Therefore, $\mathrm{Cs}^{+}$was employed as the primary ion to which the other alkali metal cation responses were compared.

The potentiometric selectivities for $\mathrm{Cs}^{+} / \mathrm{M}^{+}\left(-\log K_{\mathrm{Cs}, \mathrm{M}}{ }^{\mathrm{Pot}}\right)$ for crown ethers 2 and $\mathbf{6}$ are recorded in Table 1. A larger value of $-\log K_{\mathrm{Cs}, \mathrm{M}}{ }^{\text {Pot }}$ means a greater difference between the potentiometric response of the ionophore to the primary metal ion $\mathrm{Cs}^{+}$and that of the competing metal ion $\mathrm{M}^{+}$. The potentiometric selectivities reveal a metal ion binding strength ordering of $\mathrm{Cs}^{+}$ $>\mathrm{Rb}^{+}>\mathrm{K}^{+}>\mathrm{Li}^{+}>\mathrm{Na}^{+}$for both 2 and 6. This ordering is consistent with 2:1 (crown ether:metal ion) complexation in which the metal ion is sandwiched between two crown ether molecules.

Table 1. Potentiometric selectivities for di-(1,8-naphtho)-16-crown-4 compounds 2 and 6

\begin{tabular}{lcccccc}
\hline \multicolumn{5}{c}{$-\log K_{\mathrm{Cs}, \mathrm{M}}^{\text {Pot }}$} \\
\hline Compound & $\mathrm{M}^{+}=$ & $\mathrm{Li}^{+}$ & $\mathrm{Na}^{+}$ & $\mathrm{K}^{+}$ & $\mathrm{Rb}^{+}$ & $\mathrm{Cs}^{+}$ \\
\hline $\mathbf{2}$ & & $1.95 \pm 0.05^{\mathrm{a}}$ & $2.12 \pm 0.02$ & $1.00 \pm 0.05$ & $0.54 \pm 0.05$ & 0.0 \\
$\mathbf{6}$ & & $2.09 \pm 0.05$ & $2.46 \pm 0.05$ & $1.15 \pm 0.05$ & $0.58 \pm 0.05$ & 0.0 \\
\hline
\end{tabular}

${ }^{a}$ Standard deviations from four measurements, duplicate determinations with each of two ISEs.

\section{Experimental Section}

General. The ${ }^{1} \mathrm{H}$ and ${ }^{13} \mathrm{C}$ NMR spectra were recorded with IBM AF-200 or AF-300 spectrometers in $\mathrm{CDCl}_{3}$ with $\mathrm{Me}_{4} \mathrm{Si}$ (TMS) as internal standard. Chemical shifts $(\delta)$ are given in parts per million downfield from TMS and coupling constant $(J)$ values are in hertz. IR spectra were recorded with a Perkin-Elmer model 1600 FT-IR spectrophotometer as deposits from $\mathrm{CH}_{2} \mathrm{Cl}_{2}$ solutions onto $\mathrm{NaCl}$ plates. Melting points were determined with a Mel-Temp melting point apparatus. Elemental analysis was performed by Desert Analytics Laboratory (now Columbia Analytical Services) of Tucson, Arizona.

Reagents and solvents were obtained from commercial suppliers and used directly unless otherwise noted. $\mathrm{MeCN}$ was dried over $4 \mathrm{~A}$ molecular sieves. Powdered anhydrous $\mathrm{Cs}_{2} \mathrm{CO}_{3}$ was purchased from Chemmetall GMBH of Germany through CM Chemical Products, Inc. (Berkeley Heights, NJ).

Synthesis of 1,8-dihydroxynaphthalene (4). KOH (30.0 g, $0.53 \mathrm{~mol})$ was dissolved in water $(10 \mathrm{~mL})$ and added to a preheated ceramic crucible containing 1,8-naphthosultone $(6.00 \mathrm{~g}, 29.12$ $\mathrm{mmol})$. The mixture was heated in an oven at $250{ }^{\circ} \mathrm{C}$ for $2 \mathrm{~h}$. The black viscous mixture was 
cooled to room temperature and treated with $6 \mathrm{~N} \mathrm{HCl}(300 \mathrm{~mL})$. The mixture was extracted with $\mathrm{CH}_{2} \mathrm{Cl}_{2}(4 \mathrm{X} 50 \mathrm{~mL})$ and the combined extracts were dried over $\mathrm{MgSO}_{4}$. Activated carbon $(5 \mathrm{~g})$ was added and the mixture was stirred and filtered. The filtrate was concentrated in vacuo. The residue crystallized to produce a 54\% yield of 4 as light yellow needles with $\mathrm{mp} 138{ }^{\circ} \mathrm{C}\left(\mathrm{lit}^{11} \mathrm{mp}\right.$ $140{ }^{\circ} \mathrm{C}$. IR $3280(\mathrm{O}-\mathrm{H}) \mathrm{cm}^{-1} .{ }^{1} \mathrm{H}$ NMR $\delta$ 6.73-6.80 (m, 2H), 7.26-7.31 (m, 4H), 10.87 (s, 2H).

Synthesis of bis-1,3-(8-hydroxy-1-naphthoxy)propane (5). Under nitrogen, a solution of 4 (5.00 g, $31.25 \mathrm{mmol})$ and 1,3-dibromopropane (3.47 g, $17.18 \mathrm{mmol})$ in $\mathrm{MeCN}(150 \mathrm{~mL})$ was added dropwise during a 2-h period to a stirred and refluxing mixture of $\mathrm{K}_{2} \mathrm{CO}_{3}(6.46 \mathrm{~g}, 46.0$ $\mathrm{mmol})$ in $\mathrm{MeCN}(15 \mathrm{~mL})$. After the addition was completed, refluxing was continued for $8 \mathrm{~h}$. The mixture was cooled to room temperature and the solvent was removed in vacuo. To the residue was added $\mathrm{CH}_{2} \mathrm{Cl}_{2}$ and water. The mixture was acidified with $6 \mathrm{~N} \mathrm{HCl}$ and extracted with $\mathrm{CH}_{2} \mathrm{Cl}_{2}$ ( $3 \mathrm{X} 50 \mathrm{~mL}$ ). The combined extracts were dried over $\mathrm{MgSO}_{4}$ and evaporated in vacuo. The residue crystallized to give a $85 \%$ yield of 5 as a white solid with $\mathrm{mp} 137{ }^{\circ} \mathrm{C}$. IR $3290(\mathrm{O}-\mathrm{H}) \mathrm{cm}^{-1} .{ }^{1} \mathrm{H}$ NMR $\delta 2.55$ (pen, $\left.J=6.1 \mathrm{~Hz}, 2 \mathrm{H}\right), 4.44(\mathrm{t}, J=6.1 \mathrm{~Hz}, 4 \mathrm{H}), 6.78-6.94$ (m, $4 \mathrm{H}), 7.23-7.45(\mathrm{~m}, 8 \mathrm{H}), 9.28(\mathrm{~s}, 2 \mathrm{H}) .{ }^{13} \mathrm{C} \mathrm{NMR} \delta 29.0,65.7,105.1,110.4,115.0,119.0,122.2$, 125.6, 127.7, 136.7, 154.2, 154.9. Anal. Calcd for $\mathrm{C}_{23} \mathrm{H}_{20} \mathrm{O}_{4}: \mathrm{C}, 76.63$; H, 5.59. Found: C, 76.83; $\mathrm{H}, 5.52$.

Synthesis of di-(1,8-naphtho)-16-crown-4 (2). Under nitrogen, a solution of 5 (1.00 g, 2.77 $\mathrm{mmol})$ and the dimesylate of 1,3-propanediol (0.64 g, $2.77 \mathrm{mmol})$ in MeCN (75 mL) was added with a syringe pump over an 8-h period to a flask (equipped with a condenser and a Dean-Stark trap) containing a refluxing and stirred mixture of $\mathrm{Cs}_{2} \mathrm{CO}_{3}(2.25 \mathrm{~g}, 6.92 \mathrm{mmol})$ and $\mathrm{MeCN}$ (15 $\mathrm{mL}$ ). During the addition, the volume in the flask was maintained at $30-35 \mathrm{~mL}$ by removal of solvent with the Dean-Stark trap. After the addition was completed, the mixture was stirred overnight at $80{ }^{\circ} \mathrm{C}$ and then evaporated in vacuo. Water $(30 \mathrm{~mL})$ was added and the mixture was extracted with $\mathrm{CH}_{2} \mathrm{Cl}_{2}\left(4 \mathrm{X} 50 \mathrm{~mL}\right.$ ). The combined extracts were dried over $\mathrm{MgSO}_{4}$ and the filtrate was passed through a short bed of alumina with $\mathrm{CH}_{2} \mathrm{Cl}_{2}$-hexane (1:5) as eluent. The eluate was evaporated in vacuo and the residue was crystallized from $\mathrm{CH}_{2} \mathrm{Cl}_{2}$-hexane to give a $71 \%$ yield of white solid with mp $194{ }^{\circ} \mathrm{C}$ (dec). ${ }^{1} \mathrm{H}$ NMR $\delta 2.57$ (pen, $J=6.3 \mathrm{~Hz}, 4 \mathrm{H}$ ), $4.33(\mathrm{t}$, $J=6.3 \mathrm{~Hz}, 8 \mathrm{H}), 6.92-6.98(\mathrm{~m}, 4 \mathrm{H}), 7.24-7.46(\mathrm{~m}, 8 \mathrm{H}) .{ }^{13} \mathrm{C}$ NMR $\delta 30.1,68.3,76.7,77.0,77.3$, 110.9, 119.8, 121.9, 126.3, 137.4, 155.9. Anal. calcd for $\mathrm{C}_{26} \mathrm{H}_{24} \mathrm{O}_{4}$ : C, 77.96; $\mathrm{H}, 6.04$. Found: $\mathrm{C}$, 77.72; H, 5.87.

Synthesis of sym-(methylene)-di-(1,8-naphtho)-16-crown-4 (6). Using the same procedure as described above for the synthesis of 2 but with 3-chloro-2-chloromethyl-1-propene in place of the dimesylate of 1,3-propanediol, the eluate from the short alumina column was evaporated in vacuo and the residue was crystallized from $\mathrm{CH}_{2} \mathrm{Cl}_{2}$-EtOAc to give a $71 \%$ yield of white crystals with mp $163{ }^{\circ} \mathrm{C}$. ${ }^{1} \mathrm{H}$ NMR $\delta 2.46$ (pen, $J=6.2 \mathrm{~Hz}, 2 \mathrm{H}$ ), 4.30 (t, $\left.J=6.2 \mathrm{~Hz}, 4 \mathrm{H}\right), 4.77$ (s, 4H), 5.63 $(\mathrm{s}, 2 \mathrm{H}), 6.92-6.98(\mathrm{~m}, 4 \mathrm{H}), 7.24-7.46(\mathrm{~m}, 8 \mathrm{H}) .{ }^{13} \mathrm{C}$ NMR $\delta 30.2,68.6,71.2,110.2,111.5,117.3$, $119.8,121.7,121.9,126.1,126.4,137.4,141.7,155.6,156.6$. Anal. calcd for $\mathrm{C}_{27} \mathrm{H}_{24} \mathrm{O}_{4}$ : C, 78.61; H, 5.57. Found: C, 78.87; H, 5.89. 
Solid-state structure determination for (2). A suitable crystal for structure determination of 2 was obtained by crystallization from $\mathrm{CH}_{2} \mathrm{Cl}_{2}-\mathrm{MeOH}$. Low temperature diffraction data were collected using a Siemens Platform three-circle diffractometer coupled to a Bruker-AXS Smart Apex CCD detector with graphite monochromated Mo K $\alpha$ radiation $(\lambda=0.71073 \AA)$, performing $\varphi$ - and $\omega$-scans. Data reduction was performed with the program SAINT, version $7.12^{12}$ and semi-emperical absorption correction was performed using SADABS. ${ }^{13}$ The structure was solved by direct methods using SHELXL ${ }^{14}$ and refined against $F^{2}$ on all data by full-matrix least squares with SHELXL-97. ${ }^{15}$ All non-hydrogen atoms were refined anisotropically; all hydrogen atoms were included into the model at their geometrically calculated positions and refined using a riding model. The crystal data and experimental details are listed in Table 2.

Table 2. Crystallographic information about the structure and refinement of 2.

\begin{tabular}{ll}
\hline Empirical formula & $\mathrm{C}_{26} \mathrm{H}_{24} \mathrm{O}_{4}$ \\
\hline Formula weight $\left(\mathrm{g} \mathrm{mol}^{-1}\right)$ & 400.45 \\
Temperature $(\mathrm{K})$ & 100 \\
Crystal system & orthorhombic \\
Space group & Pna $2_{1}$ \\
$a(\AA)$ & $16.927(3)$ \\
$b(\AA)$ & $35.950(7)$ \\
$c(\AA)$ & $13.137(3)$ \\
$\alpha\left(^{\circ}\right)$ & 90 \\
$\beta\left(^{\circ}\right)$ & 90 \\
$\gamma\left(^{\circ}\right)$ & 90 \\
Volume $\left(\AA^{3}\right)$ & $7994(3)$ \\
$Z$ & 16 \\
Density (calc) $\left(\mathrm{g} / \mathrm{cm}^{3}\right)$ & 1.331 \\
Crystal size $(\mathrm{mm})$ & $0.50 \times 0.50 \times 0.30$ \\
Theta range $\left({ }^{\circ}\right)$ & 1.13 to 26.37 \\
Reflections collected & 142114 \\
Independent reflections $\left(R_{\text {int }}\right)$ & $16331(0.0441)$ \\
Completeness $(\%)$ & 99.9 \\
Data / restraints / parameters & $16331 / 2447 / 1165$ \\
Goodness-of-fit on $F^{2}$ & 1.125 \\
Final $R 1$ for $I>2 \sigma(I)$ & 0.0859 \\
Largest difference peak and hole $\left(\mathrm{e} \AA^{-3}\right)$ & 1.238 and -0.448 \\
\hline
\end{tabular}

The crystallographic data have been deposited with the Cambridge Crystallographic Data Centre (deposition number CCDC 623942) and can be obtained free of charge via www.ccdc.cam.ac.jk/data_request/cif. 
Preparation of PVC membranes and potentiometric measurements were performed as reported, ${ }^{9}$ but with $\mathrm{Cs}^{+}$as the primary ion instead of $\mathrm{Na}^{+}$and measurements for five alkali metal cation species instead of just $\mathrm{Li}^{+}, \mathrm{Na}^{+}$and $\mathrm{K}^{+}$.

\section{Acknowledgements}

Portions of this research conducted at Texas Tech University were supported by Grant D-0775 from The Welch Foundation of Houston, Texas.

\section{References}

1. Pedersen, C. J. J. Am. Chem. Soc. 1967, 89, 2495.

2. Pedersen, C. J. J. Am. Chem. Soc. 1967, 89, 7017.

3. Pedersen, C. J. Angew. Chem. 1988, 100, 1053.

4. Gokel, G. W. Crown Ethers and Cryptands; Royal Society of Chemistry, Cambridge, England, 1991.

5. Dalley, N. K.; Jiang, W.; Olsher, U. J. Incl. Phenom. Mol. Recogn. Chem. 1992, 12, 305.

6. Olsher, U.; Frolow, F.; Shoham, G.; Heo, G.-S.; Bartsch, R. A. Anal. Chem. 1989, 61, 1618.

7. Olsher, U.; Frolow, F.; Shoham, G.; Lucoch, E.; Yu, Z.-Y.; Bartsch, R. A. J. Incl. Phenom. Mol. Recogn. Chem. 1990, 9, 123.

8. Sheldrick, G. M. cell_now; Bruker-AXS, Inc., Madison, Wisconsin, 2005.

9. Ohki, A.; Lu, J.-P.; Bartsch, R. A. Anal. Chem. 1994, 66, 651.

10. Recommendations for Nomenclature of Ion-Selective Electrodes, Pure Appl. Chem. 1976, $48,127$.

11. Erdmann, M. Ann. 1888, 247, 357.

12. Chambers, J. L. SAINT 7.12; Bruker-AXS, Inc., Madison, Wisconsin, 2005.

13. Sheldrick, G. M. SADABS; Bruker-AXS, Inc., Madison, Wisconsin, 2005.

14. Sheldrick, G. M. Acta Cryst. 1990, A46, 467.

15. Sheldrick, G. M. SHELXL 97; Universität Göttingen, Göttingen, Germany, 1997. 